\title{
Nephrotic-range Albuminuria as the presenting symptom of Dent-2 disease
}

\author{
Chiara De Mutiis, Andrea Pasini, Claudio La Scola, Fabrizio Pugliese and Giovanni Montini
}

\begin{abstract}
Dent disease is a rare X-linked tubulopathy with low molecular weight proteinuria, hypercalciuria, nephrolithiasis, nephrocalcinosis and progressive renal failure. We describe the case of a 9-year-old boy who presented with nephrotic-range albuminuria at the age of 3 years. In the absence of a clear diagnosis, a renal biopsy was performed at 4 years, which revealed minimal change disease. Due to the presence of low molecular weight proteinuria, even in the absence of hypercalciuria, a diagnosis of Dent disease was considered. While there were no mutations in the CLCN5 gene, the diagnosis was confirmed by the presence of a missense mutation (p.Arg318Cys) in the OCRL gene. Conclusion: Given the large phenotypic variability of the disease and based on our experience, we believe that children with low molecular weight proteinuria, even without hypercalciuria, should be investigated for Dent disease.
\end{abstract}

Keywords: Dent disease, Low molecular weight proteinuria (LMWP), Hypercalciuria, OCRL, CLCN5, p.Arg318Cys

\section{Background}

Dent disease is a rare, $\mathrm{X}$-linked disorder characterized by low molecular weight proteinuria (LMWP), hypercalciuria, and at least one of the following criteria: nephrolithiasis, nephrocalcinosis, hematuria, hypophosphatemia or progressive renal failure [1]. Other features of proximal tubulopathy can be present, such as glycosuria, aminoaciduria and acidification defects $[1,2]$. It is caused by mutations in the CLCN5 gene (Dent-1 disease, OMIM \#300009) in $60 \%$ of cases, in the OCRL gene (Dent-2 disease, OMIM\#300555) in $~ 15 \%$ of cases,, while in the remaining $25 \%$ of cases $[3,4]$ other unidentified genes are responsible for the disease. The incidence and prevalence of Dent-1 and 2 disease are unknown. Several recent papers have reported an atypical phenotype of Dent-1 disease, presenting with high range proteinuria and LMWP as a unique clinical feature [5-8].

We describe a boy who presented with asymptomatic high range proteinuria, LMWP and normocalciuria at the age of 3 years, and who was subsequently diagnosed with Dent-2 disease with an OCRL mutation.

\footnotetext{
* Correspondence: giovanni.montini@aosp.bo.it

Nephrology and Dialysis Unit, Department of Pediatrics, Azienda

Ospedaliero-Universitaria Sant'Orsola-Malpighi Bologna, Via Massarenti 11, 40138 Bologna, Italy
}

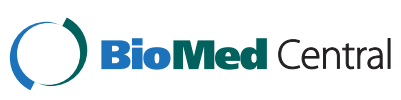

(c) 2015 De Mutiis et al. This is an Open Access article distributed under the terms of the Creative Commons Attribution License (http://creativecommons.org/licenses/by/4.0), which permits unrestricted use, distribution, and reproduction in any medium, provided the original work is properly credited. The Creative Commons Public Domain Dedication waiver (http:// creativecommons.org/publicdomain/zero/1.0/) applies to the data made available in this article, unless otherwise stated.
At the age of 10 months, the child presented with proteinuria and hematuria (urine dipstick: pH 6, S.G. 1020, $\mathrm{Hb} 1+$, Albumin 3+) following a febrile viral infection. Renal function, C3 and C4 serum levels were all normal; extractible nuclear antigen, antinuclear antibodies and anti DNA antibodies were negative. Proteinuria (600-800 mg/ day) was confirmed in subsequent evaluations without hypoalbuminemia, edema or hyperlipidemia. Kidney ultrasound was normal. There was no family history of kidney disease.

At the age of 4, he was referred to our hospital with nephrotic range proteinuria $(\mathrm{uPr} / \mathrm{uCr} \mathrm{mg} / \mathrm{mg}$ between 1.4 and 4.4), albuminuria $100-300 \mathrm{mg} / \mathrm{dl}$ and a high component of LMWP, but without hypercalciuria $(\mathrm{uCa} / \mathrm{uCr}$ $\mathrm{mg} / \mathrm{mg}: 0.38$ normal $<0.4$ for children from 3 to 5 years), nephrocalcinosis or signs of tubular damage (tubular reabsorption of phosphate $>82 \%$, absence of glycosuria and aminoaciduria). A technetium-99 m-dimercaptosuccinate (DMSA) scan revealed: "poor renal accumulation of radionuclide $3 \mathrm{~h}$ after injection". A renal biopsy was then performed which showed "minor glomerular abnormalities" typical of minimal change disease.

The child underwent regular six-monthly check-ups during which time no clinical, laboratory or renal US changes were observed. Albuminuria, LMWP were 
persistently elevated while values of urinary calcium were within the normal range for age.

On the basis of some reports of patients with Dent-1 disease, whose initial clinical presentation was proteinuria with LMWP but without hypercalciuria $[5,6]$, we decided to screen our patient for CLCN5 and OCRL1 mutations. A missense mutation (p.Arg318Cys) was identified in exon 11 of the OCRL gene. Carrier status was confirmed in the mother.

At present, the child is nine years old and has normal renal function (eGFR: $130 \mathrm{ml} / \mathrm{min} / 1.73 \mathrm{~m}^{2}$ ), proteinuria (uPr/uCr: 2.2) with albuminuria $201 \mathrm{mg} / \mathrm{L}$, alpha-1 microglobulin $329 \mathrm{mg} / \mathrm{L}$ (normal $0-12 \mathrm{mg} / \mathrm{L}$ ), and beta-2 microglobulin $128 \mathrm{mg} / \mathrm{L}$ (normal $<10.0 \mathrm{mg} / \mathrm{L}$ ), without hypercalciuria $(\mathrm{uCa} / \mathrm{uCr}: 0.24$ normal $<0.25)[9,10]$, nephrolithiasis or nephrocalcinosis. Mild elevations of muscle enzymes (CPK 332 U/L, LDH 375 U/L) have been documented, without clinical evidence of muscle weakness. Growth, intellectual development and ophthalmic examinations have all been normal up to now.

\section{Discussion}

We report a child with atypical Dent-2 disease, documented by an OCRL mutation, who presented with isolated proteinuria in the absence of any of the other classic criteria, particularly hypercalciuria. To date, approximately 250 families with Dent disease have been reported [1], of whom around 40 patients had Dent-2 disease, with various OCRL mutations described $[1,4]$.

Some studies have shown a large variability in the clinical phenotype of Dent disease, so much so that we can consider this disease to be a heterogeneous group of proximal tubular defects called "The Dent disease complex" [11]. A proportion of them have glomerular involvement, as was demonstrated in six of the nine children with Dent-1 disease presenting with asymptomatic high range proteinuria associated with LMWP, without hypercalciuria, and showing a focal segmental glomerulosclerosis and/or focal global glomerulosclerosis on biopsy [5-7]. Ludwig et al described two patients with LMWP as the only symptom of Dent-1 disease [8]. Cramer MT et al recently reported seven males with nephrotic-range proteinuria and CLCN5 mutations, two of which showed no hypercalciuria (Table 1). Our patient had a very similar clinical presentation to these patients, with the exception of minimal change disease on biopsy, which, however, was performed early in the course of the disease, perhaps before the development of sclerotic lesions.

In this respect, it is possible that these children could benefit from ACE inhibition, which may help protect the kidneys from the appearance of sclerotic lesions secondary to proteinuria. Copelovitch et al. [6] documented moderate improvement in proteinuria in a Dent patient after starting enalapril therapy, However, only a small number of the reported patients have been treated with these drugs $[5,7]$. More studies are needed in order to draw more solid conclusions.

Our patient has a missense mutation (p.Arg318Cys) in exon 11 of the OCRL gene. To our knowledge, only 6 patients with the same mutation and Dent disease have been described: two brothers by Hoopes et al. [3], one male by Sekine T. et al [9], two brothers by Böckenhauer

Table 1 Patients with Dent-1 disease in the absence of hypercalciuria reported in the literature

\begin{tabular}{|c|c|c|c|c|c|c|c|c|c|c|}
\hline Parameters & & $\begin{array}{l}\text { Patient } \\
1[5]\end{array}$ & $\begin{array}{l}\text { Patient } \\
2[5]\end{array}$ & $\begin{array}{l}\text { Patient } \\
3[5]\end{array}$ & $\begin{array}{l}\text { Patient } \\
4[5]\end{array}$ & $\begin{array}{l}\text { Patient } \\
5[6]\end{array}$ & $\begin{array}{l}\text { Patient } \\
6[7]\end{array}$ & $\begin{array}{l}\text { Patient } \\
7[7]\end{array}$ & $\begin{array}{l}\text { Patient } \\
8[8]\end{array}$ & $\begin{array}{l}\text { Patient } \\
9[8]\end{array}$ \\
\hline Age (years) & & 9 & 11 & 14 & 9 & 9 & 6 & 6 & 36 & 15 \\
\hline $\mathrm{CrCl}(\mathrm{cc} / \mathrm{min} / 1.73 \mathrm{~m} 2)$ & $>90$ & 97 & 105 & 95.5 & 126 & 79 & 98 & 135 & $>80$ & $>80$ \\
\hline S-Alb (gr/dl) & $3.5-5.3$ & 4.5 & 4.9 & 4.1 & 4.4 & 4.6 & 4.5 & 4.9 & - & - \\
\hline U-prot (mg/day) & $<200$ & $800-1000$ & $600-1400$ & $750-1100$ & 1240 & 1321 & - & - & - & - \\
\hline U-prot/U-Cr (mg/mg) & $<0.2$ & - & - & - & - & - & 3.4 & 2.6 & - & - \\
\hline U- $\beta 2 M G(m g / l)$ & $<10$ & 91.2 & 103 & 120 & 74.4 & 52.7 & - & - & $>10$ & $>10$ \\
\hline U- $\beta 2 M G(\mathrm{mcg} / \mathrm{g} \mathrm{cr})$ & $<132$ & & & & & & 166.1 & & $>132$ & $>132$ \\
\hline \multirow[t]{4}{*}{ U-Ca/U-Cr (mg/mg) } & $<0.5$ for $1-3 y$ & 0.15 & 0.14 & 0.13 & 0.12 & 0.07 & 0.18 & 0.10 & $<0.25$ & $<0.25$ \\
\hline & $<0.4$ for $3-5 y$ & & & & & & & & & \\
\hline & $<0.3$ for $5-7 y$ & & & & & & & & & \\
\hline & $<0.25$ for $>7 y$ & & & & & & & & & \\
\hline U-gluc & absent & neg & neg & neg & neg & - & - & - & - & - \\
\hline TRP (\%) & $82-95$ & 87.4 & 91.8 & 86.2 & 95.8 & & 85 & - & - & - \\
\hline $\begin{array}{l}\text { Nephrocalcinosis } \\
\text { by Renal US }\end{array}$ & & Yes & Yes & No & No & No & No & Yes & No & No \\
\hline
\end{tabular}

$\mathrm{CrCl}$ creatinine clearance, S-Alb serum albumin, U-prot urinary protein, $U$ - $\beta 2 \mathrm{MG}$ urinary beta2microglobuline, $\mathrm{U}-\mathrm{Ca} / \mathrm{U}-\mathrm{Cr}$ urinary calcium/urinary creatinine, $\mathrm{U}$-prot/U-Cr urinary protein/urinary creatinine, $U$-gluc urinary glucose, TRP tubular reabsorption of phosphate, Renal US renal ultrasound 
et al. [4] and one male by Hichri et al [12] (Table 2). Interestingly, the same mutation was identified by Hichri et al in another patient diagnosed with Lowe syndrome. The patients described by Hoopes and Böckenhauer had carrier females, as did our child, while the boy described by Sekine likely had a de novo mutation.

At diagnosis, the six patients had a mean age of 16.6 years and showed the classic hallmarks of Dent disease with LMWP and hypercalciuria, except for the patient described by Sekine, who lacked hypercalciuria and the patient reported by Hichri, whose data is not available. Two patients ( 3 and 5 in Table 2) developed a reduction in GFR during adolescence, while a renal biopsy performed only in patient 3 , demonstrated minimal change disease, as was found in our patient. This histologic finding could lead to misdiagnosis and inappropriate and ineffective therapies such as the use of corticosteroids or immunosuppressive agents.

Furthermore, patients with Dent- 2 disease may share some extra-renal symptoms with the more severe Lowe's syndrome, such as peripheral cataracts, mental impairment, growth retardation and elevated creatinine kinase and lactate dehydrogenase, without evidence of muscle weakness $[4,10]$. Regarding the p.Arg318Cys mutation, the patient with Lowe syndrome reported by Hichri et al [12] presented with severe myopia, while patients with Dent disease lack cataracts or other forms of ocular damage. An increase of CPK and LDH enzymes was present in our patient and in the two brothers described by Böckenhauer (patients 4 and 5 in Table 2). Some degree of mental impairment was detected in patients 1 and 2 and short stature was noted in patient 5 . These figures confirm that, even within the same genotype, there is a certain variability in the expression of the severity of the disease.

The absence of hypercalciuria in our patient may be due to his younger age and it is possible that he could express all the hallmarks of Dent disease in the future, but there is also the possibility that other mechanisms could regulate and compensate for the tendency to increase calcium excretion, reducing the degree of calciuria.

Therefore, the presence of hypercalciuria, typically considered pathognomonic of Dent disease, could be absent and this should be considered as part of the variability in the phenotype of this disease.

\section{Conclusion}

Dent-2 disease may have a variable phenotype, lacking all the classic hallmarks, as described for some patients with CLCN5 mutations [5-8], such that it could remain underdiagnosed.

Based on our experience and data from the literature, the diagnosis of Dent disease should be considered in all patients with high range proteinuria and LMWP, even in the absence of hypercalciuria. The CLCN5 gene, and if negative, the OCRL1 gene should be analyzed before considering a renal biopsy in males with nephrotic range proteinuria and no clinical signs of nephrotic syndrome. Extra-renal symptoms (ocular involvement, mental impairment, growth retardation and elevated creatinine kinase

Table 2 Patients with Dent-2 disease with the same missense mutation in exon 11 (p.Arg318Cys) as our patient

\begin{tabular}{|c|c|c|c|c|c|c|c|}
\hline & Patient $1 \quad[3]^{a}$ & Patient $2[3]^{a}$ & Patient 3 [9] & Patient $4[4]^{b}$ & Patient $5[4]^{\mathrm{b}}$ & Patient 6 [12] & Our patient \\
\hline Age at presentation & - & - & 7 & - & - & - & 2 \\
\hline Age at diagnosis (years) & 22 & 27 & 15 & 12 & 17 & 7 & 6 \\
\hline $\mathrm{CrCl}(\mathrm{cc} / \mathrm{min} / 1.73 \mathrm{~m} 2)$ & - & - & 90 & 107 & 77 & - & 140 \\
\hline Hypercalciuria (>0.24) & yes & yes & no & yes & yes & - & no \\
\hline LMWP & yes & yes & yes & yes & yes & yes & yes \\
\hline Low TRP (\%) & - & - & - & no & no & - & no \\
\hline Renal biopsy & - & - & $\begin{array}{l}\text { minor glomerular } \\
\text { abnormalities }\end{array}$ & - & - & - & $\begin{array}{l}\text { minimal change } \\
\text { disease }\end{array}$ \\
\hline Elevated CPK/LDH & no/no & no/no & yes/no & yes/yes & yes/yes & - & yes/yes \\
\hline glycosuria & no & no & no & no & no & - & no \\
\hline aminoaciduria & - & - & no & no & no & - & no \\
\hline Renal tubular acidosis & - & - & no & no & no & - & no \\
\hline Nephrocalcinosis/stones & no/no & no/no & no/no & yes/no & yes/no & - & no/no \\
\hline Ocular involvement & no & no & no & no & no & - & no \\
\hline Cognitive function & $\begin{array}{l}\text { mild mental } \\
\text { retardation }\end{array}$ & $\begin{array}{l}\text { mild mental } \\
\text { retardation }\end{array}$ & normal & normal & normal & normal & normal \\
\hline Growth & - & - & normal & normal & short stature & - & normal \\
\hline
\end{tabular}


and lactate dehydrogenase) should be looked for and could lead to a diagnosis of Dent-2 disease.

\title{
Consent
}

Written informed consent was obtained from the patient for publication of this Case report and any accompanying images. A copy of the written consent is available for review by the Editor-in-Chief of this journal.

\begin{abstract}
Abbreviations
CrCl: Creatinine clearance; LMWP: Low molecular weight proteinuria; TRP: Tubular reabsorption of phosphate; CPK: Creatine phosphate kinase; LDH: Lactate dehydrogenase; S-Alb: Serum albumin; U-prot: Urinary protein; U-ß2MG: Urinary beta2microglobuline; U-Ca/U-Cr: Urinary calcium/urinary creatinine; U-prot/U-Cr: Urinary protein/urinary creatinine; U-gluc: Urinary glucose; Renal US: Renal ultrasound; ACE: Angiotensinconverting enzyme.
\end{abstract}

\section{Competing interests}

The authors declare that they have no competing interests.

\section{Authors' contributions}

CD: Study conception and design of the manuscript. AP: was involved in clinical care of the patient and writing up of first draft of the paper. $C L$ and FP: were involved in clinical care and helped draft the manuscript. GM: Critical revision of the article and approved final manuscript. All authors read and approved the final manuscript.

\section{Acknowledgements}

The authors are grateful to Dr. Ian Hewitt who contributed towards the study by revising it critically and to Ms. Alexandra Rachel Teff for editing the manuscript.

Received: 19 April 2015 Accepted: 16 June 2015

Published online: 25 June 2015

\section{References}

1. Devuyst O, Thakker RV. Dent's disease. Orphanet J Rare Dis. 2010;5:28.

2. Claverie-Martín F, Ramos-Trujillo E, García-Nieto V. Dent's disease: clinical features and molecular basis. Pediatr Nephrol. 2011;26:693-704.

3. Hoopes Jr RR, Shrimpton AE, KnohI SJ, Hueber P, Hoppe B, Matyus J, et al. Dent disease with mutation in OCRL1. Am J Hum Genet. 2005;76:260-7.

4. Böckenhauer D, Bökenkamp A, Nuutinenc M, Unwind R, Van't Hoffa W, Sirimanna T, et al. Novel OCRL mutations in patients with Dent-2 disease. J Pediatr Genet. 2012;1:15-23.

5. Frishberg Y, Dinour D, Belostotsky R, Becker-Cohen R, Rinat C, Feinstein S, et al. Dent's disease manifesting as focal glomerulosclerosis: Is it the tip of the iceberg? Pediatr Nephrol. 2009;24:2369-73.

6. Copelovitch L, Nash MA, Kaplan BS. Hypothesis: Dent disease is an underrecognized cause of focal glomerulosclerosis. Clin J Am Soc Nephrol. 2007;2:914-8

7. Cramer MT, Charlton JR, Fogo AB, Fathallah-Shaykh SA, Askenazi DJ, Guay-Woodford LM. Expanding the phenotype of Proteinuria in Dent disease: a case series. Pediatr Nephrol. 2014;29:2051-4.

8. Ludwig M, Utsch B, Balluch B, Fründ S, Kuwertz-Bröking E, Bökenkamp A Hypercalciuria in patients with CLCN5 mutations. Pediatr Nephrol. 2006:21:1241-50

9. Sekine T, Nozu K, lyengar R, Fu XJ, Matsuo M, Tanaka R, et al. OCRL1 mutations in patients with Dent disease phenotype in Japan. Pediatr Nephrol. 2007;22:975-80.

10. Shrimpton AE, Hoopes Jr RR, Knohl SJ, Hueber P, Reed AAC, Christie PT, et al. OCRL1 mutations in dent 2 patients suggest a mechanism for phenotypic variability. Nephron Physiol. 2009;112:27-36.

11. Gambaro G, Vezzoli G, Casari G, Rampoldi L, D’Angelo A, Borghi L. Genetics of hypercalciuria and calcium nephrolithiasis: from the rare monogenic to the common polygenic forms. Am J Kidney Dis. 2004;44:963-86.

12. Hichri H, Rendu J, Monnier N, Coutton C, Dorseuil O, Poussou RV, et al. From Lowe syndrome to Dent disease: correlations between mutations of the OCRL1 gene and clinical and biochemical phenotypes. Hum Mutat. 2011;32:379-88.

\section{Submit your next manuscript to BioMed Central and take full advantage of:}

- Convenient online submission

- Thorough peer review

- No space constraints or color figure charges

- Immediate publication on acceptance

- Inclusion in PubMed, CAS, Scopus and Google Scholar

- Research which is freely available for redistribution 